\title{
The HPCSA's telemedicine guidance during COVID-19: A review
}

\author{
B A Townsend, ' BA, LLB, LLM, PGDip, PhD; M Mars, ${ }^{2,3}$ MB ChB, MD; R E Scott, ${ }^{2,4}$ PhD, BSc Hons \\ 'School of Law, Howard College, University of KwaZulu-Natal, Durban, South Africa \\ ${ }^{2}$ Department of TeleHealth, College of Health Sciences, University of KwaZulu-Natal, Durban, South Africa \\ ${ }^{3}$ College of Nursing and Health Sciences, Flinders University, Adelaide, South Australia \\ ${ }^{4}$ Department of Community Health Sciences, Cumming School of Medicine, University of Calgary, Alberta, Canada
}

Corresponding author: B A Townsend (bev@greymatter.co.za)

\begin{abstract}
The coronavirus disease 2019 (COVID-19) pandemic has raised interest in the application of e-health or d-health (digital health) innovations throughout the world. Many countries have rapidly developed, refined or retooled e-health solutions and existing legislation and guidelines to permit their swift implementation. It is anticipated that these events will stimulate sustained change in the interest in and use of e-health (e.g. telehealth, telemedicine, m-health (mobile health), e-learning and health informatics). The stance of the Health Professions Council of South Africa (HPCSA) has hampered this response, initially even in the face of the pandemic. This article reviews recent events in SA, relevant World Medical Association statements and international COVID-19-related responses. It concludes that the HPCSA must acknowledge global experience, and provide SA with clear, evidence-based and clinically practicable guidelines that promote and sustain the use of telemedicine broadly, now and post COVID-19.
\end{abstract}

SAfr J Bioethics Law 2020;13(2):97-102. https://doi.org/10.7196/SAJBL.2020.v13i2.725

The outbreak of coronavirus disease 2019 (COVID-19) began in Wuhan, China in December 2019, was first reported in late 2019, and spread rapidly. ${ }^{[1]}$ The World Health Organization (WHO) declared the outbreak a global public health emergency of international concern in January 2020, then upgraded this to a pandemic on 11 March 2020.[2] South African (SA) President Cyril Ramaphosa declared a State of Disaster in SA on 15 March $2020,{ }^{[3]}$ with a national lockdown effective from 26 March 2020.[4]

Telemedicine, using information and communications technologies (ICT) to provide health information and healthcare remotely (without requiring face-to-face interaction), is used throughout the world. ${ }^{[5]}$ In response to the health crisis and to the use of telemedicine by various actors within $S A$, the Health Professions Council of SA (HPCSA) released three notices (Fig. 1): on 9 March 2020, 'Guidelines on telemedicine in SA'; ${ }^{\prime[6]}$ on 26 March 2020, 'Guidance on the application of telemedicine guidelines during the COVID-19 pandemic'; ${ }^{18]}$ and on 3 April 2020, 'Notice to amend telemedicine guidelines during COVID-19! ${ }^{\prime[10]}$ Response from the SA Medical Association (SAMA $)^{[9]}$ and unrelated action by the Allied Health Professions Council of South Africa (AHPCSA) $)^{[7]}$ forced the HPCSA to modify their position. However, these new HPCSA guidances provide only a temporary reprieve and appear to only reinforce the restrictive position adopted by the HPCSA in booklet 10, 'General ethical guidelines for good practice in telemedicine' (referred to hereafter as 'the guidelines') regarding the application of various telemedicine models. ${ }^{[1]]}$

The HPCSA's initial stimulus was evidence of health practitioners performing remote patient and provider telemedicine in response to COVID-19, in contravention of guidelines which have been challenged for their lack of insight and practicality. ${ }^{[9,12]}$ This amid recent media reports indicating that Discovery Health and Vodacom have, or are in the process of, launching a virtual e-health platform, ${ }^{[13]}$ comments by President Cyril Ramaphosa that 'we want a SA with a high-tech economy where advances in e-health, robotics and remote medicine are applied as we roll out the NHI [National Health Insurance] ${ }^{r[14]}$ and a national digital health strategy document showing the intent and direction of the government. ${ }^{[15,16]}$ Despite belated concessions in their 3 April 2020 release, the HPCSA offers little practical support for postCOVID-19 use of telemedicine. They also fail to address their position regarding face-to-face consultations, physical examinations and virtual prescribing, among other issues.

The main 'mischief' the HPCSA wished to restrain was the treatment of patients directly and remotely by health practitioners without a practitioner's physical presence (at the patient's location) and where there was no pre-existing practitioner-patient relationship. However, up to 9 March 2020, the HPCSA's view of telemedicine was ambiguous. Clause 3.1 of the guidelines ${ }^{[11]}$ and the 9 March release ${ }^{[6]}$ both state that telemedicine 'means between a healthcare practitioner in one location and a healthcare practitioner in another location', and clause 3.4 of the guidelines ${ }^{[11]}$ refers to a 'consulting healthcare practitioner' who is 'the practitioner who conducts a 'face-to-face' interview or examination with the patient' (i.e. must be physically present with the patient). This appears to preclude direct and remote patient-provider interaction (i.e. without a consulting healthcare practitioner present with the patient). Yet, clause 4.8.1(a) ${ }^{[11]}$ refers to 'patient-initiated' telemedicine, without further explanation or definition.

If direct and remote patient-provider interaction (without a consulting healthcare practitioner present with the patient) is not permitted, this position negates the essence of telemedicine: the replacement of a physical presence with a remote one, thereby enhancing access to healthcare where doctor (or healthcare provider) presence may not be 


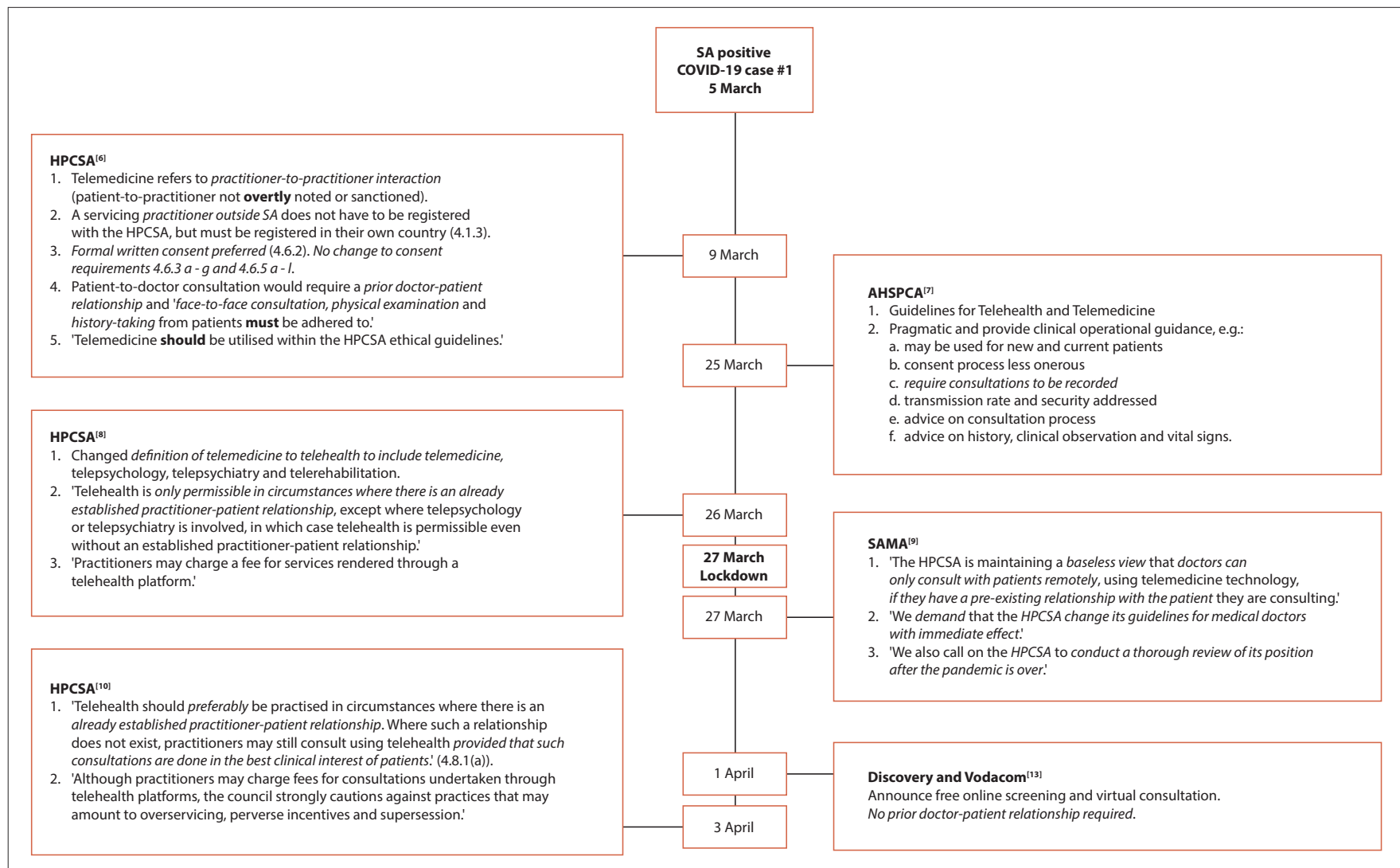

Fig. 1. Timeline of media releases and some key content from HPCSA, SAMA, and AHPCSA (italicised content for emphasis). Note: the parenthetical numbers identified in each box refer to the relevant sections in the 2014 HPCSA guidelines. ${ }^{[1]}$ (SA = South Africa; HPCSA = Health Professions Council of SA; $A H P C S A=$ Allied Health Professions Council of SA; SAMA = SA Medical Association.)

possible or, as currently, undesirable. The repeated requirement for an 'established practitioner-patient relationship' is also ambiguous. It is defined in clause 4.2.1 of the guidelines ${ }^{[1]]}$ as 'the relationship between the patient and the healthcare practitioner ... established when the practitioner agrees to treat the patient and the patient agrees to be treated.' This can be achieved remotely, as done in other countries.

\section{At issue}

The promise of telemedicine and its enormous value, especially in critical times, is that it can be practised remotely, or from a distance. Yet the HPCSA seems reticent to exploit the virtue of this benefit. Instead of providing clear guidance on how such benefit may be harnessed ethically to improve medical practice and patient health, it persists with insistent and mandatory requirement for notions such as physical examinations, practitioner-patient relationships and face-toface consultations in every situation. Although helpful and undeniably necessary in some contexts, experience is showing that face-to-face consultations are not always necessary, or can be achieved remotely, particularly when in the grip of a pandemic.

At issue is whether the approach of the HPCSA is informed, appropriate, and ethically responsible given the unprecedented and immediate threat of contagion and the ongoing resource constraints of SA. Therefore, what ought the HPCSA be doing, and should telemedicine be embraced constructively, as it is elsewhere in the world?

\section{Informed: International perspective}

Given a wealth of global insight, the HPCSA's stance is not in line with experience and action elsewhere. The application of e-health (or increasingly digital health (d-health)) in health and healthcare, including telehealth and telemedicine, has tremendous depth and breadth. ${ }^{[17]}$ Routine guidance and emergency guidance in the use of e-health (including telehealth and telemedicine) are available.

\section{Routine guidance}

The guidelines ostensibly align with the World Medical Association (WMA) statement of 2007, ${ }^{[18]}$ amended in 2018. ${ }^{[19]}$ However, the HPSCA and WMA statements diverge on some key issues, and the guidelines misinterpret or lack clarity on many issues. In addition, Table 1 shows awareness of the dynamic nature of e-health. Two earlier WMA statements (1992 and 1999) ${ }^{[20,21]}$ have been rescinded and another (2007) ${ }^{[18]}$ amended to accommodate growing awareness and use of, and changing technology and evidence for, e-health. The HPSCA has lacked similar action, with many identified limitations not being addressed before final promulgation of the guidelines.

While the WMA also notes the term 'telehealth' (WMA 2009), ${ }^{[22]}$ it does not replace telemedicine with telehealth, as the HPCSA has done (29 March release, Fig. 1). Rather the WMA simply acknowledges the broader 'range of activities that support the patient and the public in being healthy' embraced by telehealth (in concert with global opinion) acknowledging that 'physicians play an important role' in 'prevention, promotion, diagnostic self-care and treatment'. It is largely accepted that there is a distinction between telemedicine and telehealth. Telemedicine is the practice by clinicians in the medical, rehabilitation or sometimes nursing professions. In contrast, telehealth subsumes telemedicine, and relates to the broader application of ICT in interactions made by healthcare providers other than those 
in the medical, rehabilitation or nursing professions, i.e. allied health professionals.

The WMA also fully endorses telemedicine between a physician and a patient (Table 1), which the HPCSA does not overtly do in the guidelines. The HPCSA makes certain allowances in this regard in its 26 March release, and again in the 3 April release (Fig. 1), although this is 'only applicable during the COVID-19 pandemic' or until the HPCSA retracts this relaxation. Thus, the long-term utility of telemedicine by licensed doctors remains unclear.

In its 26 March release, the HPCSA notes that 'telemedicine should be utilised within the HPCSA ethical guidelines'; these guidelines have several implications that have been challenged, e.g. physical examination and signed written consent. ${ }^{[12]}$ It also states that telehealth is only permissible in circumstances where there is an already established practitioner-patient relationship, except where telepsychology and/or telepsychiatry is involved (26 March release, Fig. 1). While the WMA notes that telehealth 'challenges the conventional perception of the physician-patient relationship' (Table 1), ${ }^{[22]}$ it does not mandate that such a relationship be a prerequisite. Under pressure from SAMA (27 March release, Fig. 1), the HPCSA adjusted its position (3 April release), saying that 'telehealth should preferably be practised' where a prior patient-physician relationship exists.

Table 1. Timeline of statements and some key content (WMA)

\begin{tabular}{|c|c|}
\hline Year & Statement title, effective dates and some key content \\
\hline 1992 & $\begin{array}{l}\text { WMA statement on home medical monitoring, 'telemedicine' and medical ethic }{ }^{[20]} \\
\text { Adopted by the 44th World Medical Assembly Marbella, Spain, September } 1992 \\
\text { Rescinded at the WMA General Assembly, Pilanesberg, SA, } 2006\end{array}$ \\
\hline 1999 & $\begin{array}{l}\text { WMA statement on accountability, responsibilities and ethical guidelines in the practice of telemedicine }{ }^{[21]} \\
\text { Adopted by the } 51 \text { st World Medical Assembly, Tel Aviv, Israel, October } 1999 \\
\text { Rescinded at the WMA General Assembly, Pilanesberg, SA, } 2006\end{array}$ \\
\hline 2007 & $\begin{array}{l}\text { WMA statement on the ethics of telemedicine }{ }^{[18]} \\
\text { Adopted by the 58th WMA General Assembly, Copenhagen, Denmark, October } 2007 \\
\text { Amended by the 69th WMA General Assembly, Reykjavik, Iceland, October } 2018\end{array}$ \\
\hline 2009 & $\begin{array}{l}\text { WMA statement on guiding principles for the use of telehealth for the provision of healthcare }{ }^{[2]} \\
\text { Adopted by the 60th WMA General Assembly, New Delhi, India, October } 2009 \\
\text { - The WMA defines telemedicine as 'the practice of medicine over a distance, in which interventions, diagnostics and treatment } \\
\text { decisions and recommendations are based on data, including voice and images, documents and other information transmitted } \\
\text { through telecommunication systems'. This could include telephone and internet. } \\
\text { - A broader telehealth definition brings into play the entire range of activities that support the patient and the public in being healthy: } \\
\text { prevention, promotion, diagnostics self-care and treatment are all areas where physicians play an important role. It is this } \\
\text { broader definition that the WMA endorses. } \\
\text { - While this statement focuses mainly on telehealth encounters between patients and health professionals, it should be noted } \\
\text { that another important aspect of telehealth is the use of telecommunication between health professionals when providing } \\
\text { healthcare. } \\
\text { - While the practice of telehealth challenges the conventional perception of the physician-patient relationship, there is a 'duty of } \\
\text { care' established in all telehealth encounters between the physician and the patient, as in any healthcare encounter. }\end{array}$ \\
\hline 2015 & $\begin{array}{l}\text { WMA statement on mobile health } \\
\text { Adopted by the } 66 \text { th WMA General Assembly, Moscow, Russia, October } 2015 \\
\text { 'Physicians who use m-health ... should heed the ethical guidelines set out in the WMA Statement on Guiding Principles for the } \\
\text { Use of Telehealth for the Provision of Health Care' (2009). }\end{array}$ \\
\hline 2018 & $\begin{array}{l}\text { WMA statement on the ethics of telemedicine }{ }^{[24]} \\
\text { Adopted by the 58th WMA General Assembly, Copenhagen, Denmark, October } 2007 \\
\text { Amended by the 69th WMA General Assembly, Reykjavik, Iceland, October } 2018 \\
\text { - Telemedicine is the practice of medicine over a distance, in which interventions, diagnoses, therapeutic decisions, and } \\
\text { subsequent treatment recommendations are based on patient data, documents and other information transmitted through } \\
\text { telecommunication systems. } \\
\text { - Telemedicine can take place between a physician and a patient or between two or more physicians, including other healthcare } \\
\text { professionals. } \\
\text { - The development and implementation of information and communication technology are creating new and different ways of } \\
\text { practising medicine. } \\
\text { Autonomy and privacy of the physician: } \\
\text { 6. A physician should not participate in telemedicine if it violates the legal or ethical framework of the country. } \\
\text { 8. The physician should exercise their professional autonomy in deciding whether a telemedicine versus face-to-face consultation } \\
\text { is appropriate. } \\
\text { 9. A physician should exercise autonomy and discretion in selecting the telemedicine platform to be used. } \\
\text { Recommendations: } \\
\text { 3. Telemedicine should not be viewed as equal to face-to-face healthcare and should not be introduced solely to cut costs or as a } \\
\text { perverse incentive to overservice and increase earnings for physicians. } \\
\text { 5. New technologies and styles of practice integration may require new guidelines and standards. }\end{array}$ \\
\hline
\end{tabular}




\section{Emergency guidance (response to COVID-19)}

Support for and application of e-health, e.g. telehealth, telemedicine, m-health (mobile health) and health informatics, to address the COVID19 pandemic has been pronounced, swift, and global (Table 2). Other examples include chatbots (or 'conversational agents') that mimic human speech that are powered by artificial intelligence algorithms to create symptom checkers to screen patients, or to retain contact with quarantined patients. Other systems have been used to check health metrics (temperature, blood pressure, blood sugar) in COVID-19 patients with pre-existing conditions rendering them more susceptible to the disease.

COVID-19 has acted as a global catalyst for the implementation or growth of many aspects of e-health, not only telemedicine. Healthcare providers, consumers, industry, governments and regulators have moved rapidly to accommodate the need. This trend is anticipated to be long-term, firmly establishing e-health (digital health) in the routine practice of medicine, and health and healthcare.

\section{Appropriate: Telemedicine in the time of COVID-19}

Infection is acquired through respiratory droplets and contact through close (within 2 metres) or direct contact with infected people and with surfaces or objects used by an infected person. ${ }^{[24]}$ The traditional approach, as prescribed by the existing guidelines and first release (9 March 2020, Fig. 1), was that people who developed the symptoms of COVID-19 (fever, cough and shortness of breath) should physically visit a primary care doctor, another healthcare provider or an emergency room. The health professional should then conduct a face-to-face consultation and a physical examination. However, is this approach advisable in the midst of a global pandemic when treating potentially contagious people, and when personal protective equipment is in short supply? By insisting that potentially infected persons openly travel to their doctor's waiting rooms, the HPCSA placed many more lives at risk. Instead, by urging those displaying symptoms to connect remotely to a doctor through telemedicine, their symptoms can be triaged while still in relative isolation, which was only acknowledged in the 3 April release. ${ }^{[10]}$

By using a consequentialist framework to bring about the best future outcomes (to save lives, support public health and assist the already strained healthcare system), what might be the best route forward? To garner trust, such a heuristic response to telemedicine by the HPCSA should at all times, but especially in crisis, $(i)$ be informed; (ii) be proportional to the seriousness of the public health threat; (iii) promote what is necessary to achieve a specific publichealth objective; and (iv) be reasonable and justified. ${ }^{[25]}$ The evidence favours the expanded use of telemedicine. The public health threat of the pandemic is unprecedented, and will prevail for an uncertain period. The literature and social media demonstrate that telemedicine capabilities are available to be used. Common sense also indicates that broader implementation of telemedicine is reasonable and justified.

\section{Ethically responsible?}

The guidelines ${ }^{[11]}$ and recent communications $s^{[6,8,10]}$ raise concerns. They:

(i) are not in accordance with international developments;

(ii) largely ignore the beneficial role telemedicine might play in the COVID-19 crisis;

(iii) inadequately address ongoing issues such as requiring faceto-face consultations and physical examinations, prescribing and the need for a doctor-patient relationship within a virtual context;

(iv) are ambiguous and lack definitions for important terms such as 'should' and 'must'; and,

(v) provide little reasonable expectation of a workable path forward post COVID-19.

Two presumptions of the HPCSA appear to linger regarding 'doctorpatient relationships', 'physical examinations' and 'face-to-face consultations'. First, that they are always necessary and cannot be addressed virtually. Second, that practising telemedicine without them poses an unacceptable risk and threat to the patient. These presumptions are at the very least moot, and carry little or no evidential validity.

Furthermore, social norms guide the behaviour and practice that society deems acceptable at any given time and place. It is incumbent on entities that develop ethical standards for telemedicine to closely align their guidelines with evolving social norms. Failure to do so amounts to the'unethical deprivation of the benefits such technologies hold, particularly to those most vulnerable in our society who stand to benefit the most.[26]

Table 2. Actions taken recently by various countries to implement or expand use of e-health in response to COVID-19

\begin{tabular}{ll}
\hline Country & COVID-19-related response to use of e-health \\
\hline Canada & Doctors are 'advised to provide telemedicine or virtual care when possible' during the COVID-19 \\
& pandemic; patients are urged to remotely triage using one of three methods before attending a \\
& clinic \\
Japan & Free remote health consultation service launched in response to the pandemic \\
Israel & Telehealth adopted in treating quarantined patients on hospital grounds and at home \\
UK & NHS informs all GPs 'all practices are now being advised to change face-to-face appointments \\
USA & booked online to triage appointments via telephone or video' \\
& FDA and CDC implement measures to make telemedicine more accessible to patients and \\
Saudi Arabia, Singapore (and elsewhere) & healthcare providers, reducing contact and exposure to COVID-19, and promote availability and \\
New Zealand & use of telehealth, telemedicine, or nurse advice lines \\
Australia & Introduce a cellphone app for COVID-19 self-diagnosis and consultations \\
Brazil & Funding to scale-up capacity of community healthcare providers to perform consultations online \\
Singapore & Funding for healthcare providers to deliver services over the phone or by video-conferencing
\end{tabular}

NHS = National Health Service; GP = general practitioner; FDA = Food and Drug Administration; $\mathrm{CDC}=$ Centers for Disease Control and Prevention; $\mathrm{Al}=$ artificial intelligence . 
The ethical issue of not making available technologies found to significantly improve access and clinical outcomes has been questioned. ${ }^{[27]}$ It is unethical not to use telemedicine in settings with limited access, not learn from the experience of others and not to implement solutions that have been proven to be effective and appropriate. ${ }^{[2,27]}$ Technological innovations are themselves neither ethical nor unethical; it is how they are used that renders them either ethical or not. Telemedicine, like any novel and evolving healthcare technology, should be used to promote optimal functioning of the healthcare professional, and emphasise (rather than detract from) the humanity of the health provider, and of the patient. ${ }^{[15]}$

\section{What next?}

Acknowledging and respecting that the HPCSA is a statutory body whose role is to protect patients against possible abuse, and to safeguard and provide guidance to healthcare practitioners, what can and should the HPCSA do? In the present circumstances and in the future the HPCSA must weigh the risk against the reward - what is the potential harm to life and health of patients of using telemedicine by qualified and registered health professionals weighed against the risk of harm to healthcare providers and the populace by not using such technologies? As the answer seems self-evident, how should this be permitted?

The nature of COVID-19 suggests that close physical contact should be avoided where possible. The HPCSA must more overtly consider that: $S A$ is in a national health emergency; our human and infrastructure resources are stretched; many people have access (directly or indirectly) to digital devices; and new paradigms can contribute in a clinically meaningful way - with the caveat that appropriate and necessary guidance and oversight be provided.

This need not compromise public safety. The HPCSA would better serve public safety and fulfil its mandated responsibility by providing practical and robust guidance and direction on how and under what circumstances these technologies can best be practically applied. Being too proscriptive leads to inflexible and impracticable advice that cannot be implemented in either emergency or normal settings, or that will be ignored. Any position adopted as an interim measure in this crisis, and that better supports the use of telemedicine in future, should be reviewed and adopted as appropriate after this crisis has been successfully addressed. This necessitates a thorough review and revision of the 2014 HPCSA guidelines, ${ }^{[1]]}$ seeking broad input from stakeholders and experts, and impartial consideration of their input.

The SA President and the Minister of Health have promoted the use of telemedicine in the fight against COVID-19. The evidence shows that there is a place for its responsible and appropriate use, particularly in times of an unprecedented public health emergency, but also after the crisis has been resolved. The challenge is to balance the right to access public health with urgent public need that does not compromise public safety. This can be achieved, but requires the HPCSA to acknowledge global experience, to act proactively and collaboratively, and to provide clear, prudent, reasonable and clinically practicable guidance.

Acknowledgements. None.

Author contributions. Equal contributions.

Funding. None.

Conflicts of interest. None.
1. World Health Organization. Novel Coronavirus (2019-nCoV) Situation Report - 1. Geneva: WHO, 21 January 2020. https://www.who.int/docs/ default-source/coronaviruse/situation-reports/20200121-sitrep-1-2019-ncov. pdf?sfvrsn=20a99c10_4 (accessed 12 April 2020).

2. World Health Organization. Director-General's opening remarks at the media briefing on COVID-19. Geneva: WHO, 11 March 2020. https://www.who.int/dg/ speeches/detail/who-director-general-s-opening-remarks-at-the-media-briefingon-covid-19---11-march-2020 (accessed 12 April 2020).

3. Statement by President Cyril Ramaphosa on measures to combat COVID-19 epidemic. 15 March 2020. https://www.gov.za/speeches/statement-presidentcyril-ramaphosa-measures-combat-covid-19-epidemic-15-mar-2020-0000 (accessed 12 April 2020).

4. President Cyril Ramaphosa: Escalation of measures to combat Coronavirus COVID-19 pandemic. 23 March 2020. https://www.gov.za/speeches/presidentcyril-ramaphosa-escalation-measures-combat-coronavirus-covid-19-pandemic23-mar (accessed 12 April 2020).

5. World Health Organization. eHealth at WHO. Geneva:WHO, 2020. http://www.who. int/ehealth/about/en/ (accessed 12 April 2020).

6. Health Professions Council of South Africa. Media Statement: Guidelines on Telemedicine in South Africa. Pretoria: HPCSA, 9 March 2020. https://www.hpcsa. co.za/Uploads/Press\%20Realeses/2020/Guidelines to telemedicine in South Africa.pdf (accessed 8 October 2020).

7. Allied Health Professions Council of South Africa. Guidelines: Telehealth and telemedicine as a result of South African state of disaster. Pretoria: AHPCSA, 25 March 2020. https://ahpcsa.co.za/wp-content/uploads/2020/03/GUIDELINES TELEHEALTH-TELEMEDICINE_1_24Mar2020.pdf (accessed 12 April 2020).

8. Health Professions Council of South Africa. Guidance on the application of Telemedicine guidelines during the COVID-19 pandemic. Pretoria: HPCSA, 26 March 2020. https://www.hpcsa.co.za/Uploads/Events/Announcements/ APPLICATION_OF_TELEMEDICINE_GUIDELINES.pdf (accessed 12 April 2020).

9. South African Medical Association. Open letter protesting against the Health Professions Council of South Africa (HPCSA) Guidelines on Telemedicine during the Covid-19 pandemic. Pretoria: SAMA, 27 March 2020. https://www.samedical.org/ cmsuploader/viewArticle/1098 (accessed 12 April 2020).

10. Health Professions Council of South Africa. Notice to amend telemedicine guidelines during COVID-19. Pretoria: HPCSA, 3 April 2020. https://www. hpcsa-blogs.co.za/notice-to-amend-telemedicine-guidelines-during-covid-19/ (accessed 12 April 2020).

11. Health Professions Council of South Africa. General Ethical guidelines for good practice in telemedicine. Booklet 10. Pretoria: HPCSA, 2014. https://www.hpcsa. co.za/Uploads/Professional_Practice/Conduct $\% 20 \% 26 \% 20$ Ethics/Booklet $\% 20$ 10\%20Telemedicine\%20September\%20\%202016.pdf (accessed 12 April 2020).

12. Townsend BA, Mars M, Scott RE. The development of ethical guidelines for telemedicine in South Africa. S Afr J Bioethics Law 2019;12(1):19-26. https://doi. org/10.7196/SAJBL.2019.v12i1.662

13. Discovery and Vodacom are giving free virtual COVID-19 consults. Business Day, 1 April 2020. https://www.businesslive.co.za/bd/national/2020-04-01-discoveryvodacom-giving-free-virtual-COVID-19-consults/ (accessed 12 April 2020).

14. President Cyril Ramaphosa. State of the Nation Address 2019. 20 June 2019. https:// www.gov.za/speeches/2SONA2019 (accessed 12 April 2020).

15. Department of Health, South Africa. National Digital Health Strategy for South Africa 2019 - 2024. Pretoria: NDoH, 2019. http://www.health.gov.za/index. php/2014-08-15-12-54-26?download=3651: national-digital-health-strategy-forsouth-africa-2019-2024 (accessed 12 April 2020).

16. Presidential Health Summit. Strengthening the South African health system towards an integrated and unified health system. 2018. https://www.gov.za/ sites/default/files/gcis_document/201902/presidential-health-summit-report.pdf (accessed 12 April 2020)

17. World Health Organization. Classification of digital health interventions v1. 0: A shared language to describe the uses of digital technology for health. Geneva: WHO 2018. https://apps.who.int/iris/handle/10665/260480 (accessed 12 April 2020).

18. World Medical Association. WMA Statement on the Ethics of Telemedicine. Adopted by the 58th WMA General Assembly, Copenhagen, Denmark, October 2007.

19. World Medical Association. WMA Statement on the Ethics of Telemedicine. Amended by the 69th WMA General Assembly. Reykjavik, Iceland, October 2018

20. World Medical Association. World Medical Association statement on home medical monitoring, telemedicine and medical ethics. Adopted by the 44th World Medical Assembly, Marbella, Spain, September 1992.

21. World Medical Association. World Medical Association statement on accountability, responsibilities and ethical guidelines in the practice of telemedicine. Adopted by the 51st World Medical Assembly, Tel Aviv, Israel, October 1999.

22. World Medical Association. WMA Statement on guiding principles for the use of telehealth for the provision of health care. Adopted by the 60th WMA General Assembly, New Delhi, India, October 2009

23. World Medical Association. WMA Statement on Mobile Health. Adopted by the 66th WMA General Assembly, Moscow, Russia, October 2015. 
24. World Health Organization. Modes of transmission of virus causing COVID-19: Implications for IPC precaution recommendations - scientific brief. Geneva: WHO 29 March 2020. https://www.who.int/news-room/commentaries/detail/modesof-transmission-of-virus-causing-covid-19-implications-for-ipc-precautionrecommendations (accessed 12 April 2020).

25. Cummings L. The 'trust' heuristic: Arguments from authority in public health Health Communication 2014;29(10):1043-1056. https://doi.org/10.1080/1041023 6.2013 .831685
26. Mars M, Scott RE. Being spontaneous: The future of telehealth implementation? Telemed e-Health 2017;23(9):766-772. https://doi.org/10.1089/tmj.2016.0155

27. Fleming DA, Edison KE, Pak H. Telehealth ethics. Telemed e-Health 2009;15(8):797803. https://doi.org/10.1089/tmj.2009.003

Accepted10 June 2020 